\title{
Effect of $\gamma$-irradiation on the physicochemical properties, and microbial and sensory qualities of cold-stored onion puree.
}

\begin{abstract}
The present study was conducted to evaluate the effect of different doses $(0,1,2,3,5$ and 7 $\mathrm{kGy})$ of $\gamma$-irradiation on the physicochemical properties $(\mathrm{pH}$, titratable acidity, total soluble solid, color, organic acid content), and also the microbial and sensory qualities of onion puree during cold storage at $4 \mathrm{C}$ for 28 days. The different doses of $\gamma$-irradiation were found to not have any negative effect on titratable acidity, $\mathrm{pH}$, total soluble solid and organic acid contents of onion puree immediately after irradiation and also during cold storage. Irradiation at $3 \mathrm{kGy}$ and above was able to control the development of yeasts and molds in the onion puree, but had negative effects on the color and sensory quality of the onion puree. This study indicates that irradiation at $2 \mathrm{kGy}$ reduced microbial counts with minimum adverse effects on color and sensory qualities.
\end{abstract}

Keyword: Onion puree; G-irradiation; Physicochemical properties; Storage. 